\title{
Yvonne Picard e a fenomenologia entre Husserl e Heidegger
}

\author{
Yvonne Picard and the phenomenology between \\ Husserl and Heidegger
}

Fabio Caprio Leite de Castro ${ }^{1}$

\begin{abstract}
Resumo: Este artigo tem por objetivo apresentar e avaliar o pensamento da filósofa Yvonne Picard, a partir do único texto por ela publicado, Le temps chez Husserl et chez Heidegger. Por ser uma filósofa pouco conhecida no Brasil, será feita uma breve contextualização do seu escrito, que se insere em um momento decisivo para a recepção da fenomenologia na França, ao final dos anos 1930 e início dos anos 1940. Depois disso, mostraremos em diferentes etapas como ela procurou confrontar a filosofia de Heidegger à de Husserl através da fenomenologia da consciência do tempo. Pretendemos mostrar, ao final, como a sua solução retorna a Husserl com base em uma perspectiva dialética.
\end{abstract}

Palavras-chave: Yvonne Picard, fenomenologia, tempo, dialética.

\begin{abstract}
This article aims to present and evaluate the philosopher Yvonne Picard's thinking, based on the only text she has published, Le temps chez Husserl et chez Heidegger. Because she's a little-known philosopher in Brazil, a brief contextualization of her writing will be made, which is part of a decisive moment for the reception of phenomenology in France in the late 1930's and early 1940's. After that, we'll show in different stages how she sought to confront Heidegger's philosophy with Husserl's trough the phenomenology of time-consciousness. We intend to show at the end how her solution returns to Husserl based on a dialectical perspective.
\end{abstract}

Keywords: Yvonne Picard, phenomenology, time, dialectic.

\section{Introdução}

Este artigo tem por escopo geral a apresentação e análise do pensamento de Yvonne Picard, uma talentosa filósofa que já se fazia brilhar em fenomenologia quando ainda jovem, com 23 anos, em razão das atrocidades da segunda Guerra, foi deportada e morta no campo de concentração de Birkenau. 
Como se trata de uma pensadora em geral esquecida, ou mesmo, entre nós, no Brasil, praticamente desconhecida, propõe-se em um primeiro ponto uma contextualização do único escrito filosófico que dela conhecemos. Yvonne Picard estudou filosofia e escreveu no período entre Guerras, tempo de efervescência filosófica na França. Foi aluna de Merleau-Ponty, aproximou-se de Sartre na resistência e foi estagiária de Simone de Beauvoir; frequentou os cursos de Kojève e Jean Wahl. Por si só, o seu texto, de 1941, é de importância historiográfica e filosófica para os interessados nos caminhos peculiares da fenomenologia francesa.

Após esse breve apanhado contextual que se considera aqui necessário ao restante da exposição, será realizada uma abordagem do seu texto sobre a fenomenologia da consciência do tempo. Os principais objetivos desta abordagem serão (1) elucidar o ponto de partida adotado pela filósofa na confrontação entre Husserl e Heidegger; (2) retomar a fenomenologia de Husserl em seus aspectos essenciais; (3) desenvolver algumas considerações sobre o caráter dialético do tempo; (4) apresentar as razões finais da crítica à concepção heideggeriana de autenticidade.

Com isso, serão apresentadas criticamente as ideias de Yvonne Picard que puderam chegar até nós, reconhecendo-se a importância do seu trabalho filosófico para a fenomenologia.

\section{O triste fim de uma promissora filósofa}

Aquilo que será aqui explanado se deve ao trabalho realizado por Daniel Giovannangeli, que em 2008 recuperou o texto da edição original de Yvonne Picard e revisou-o para publicação na Revue Philosophie, com o título Le Temps chez Husserl et chez Heidegger. ${ }^{2}$ Além disso, na Apresentação do texto, Giovannangeli fornece o conjunto de informações e pistas biográficas e dos comentários de Levinas e Derrida à obra de Picard, que constituem a base destas considerações preliminares. ${ }^{3}$

Yvonne Picard nasceu em 1920 em Atenas e morreu em o9 de março de 1943 em Birkenau. (Auschwitz II), com a idade de 23 anos. Em sua juventude violentamente interrompida, participou juntamente com Simone de Beauvoir, Dominique Desanti e Jean-Toussaint Desanti do

\footnotetext{
${ }^{2}$ PICARD, Yvonne. "Le temps chez Husserl et chez Heidegger". Philosophie, nº 100, 2008, éditions Minuit, p. 07-37. ${ }^{3}$ GIOVANNANGELI, Daniel. "Présentiation”. Philosophie, $\mathrm{n}^{\circ}$ 100, 2008, éditions Minuit, p. o3-o6.
} 
grupo de resistência Socialismo e Liberdade fundado por Sartre no seu retorno do cativeiro em 1941. Junta-se logo depois às Juventudes Comunistas e acaba sendo detida em junho de $1942 .{ }^{4}$ Através das referências de Giovannangeli, podemos encontrar, em um dos raros artigos sobre o tema, L'histoire d'Yvonne Picard, de Bianca Lamblin, a reconstituição das condições históricas desta prisão. ${ }^{5}$

A narrativa do artigo de Bianca Lamblin foi escrita primordialmente por quatro amigos de Yvonne Picard, desejosos de testemunhar sobre quem ela foi: Collete Duchatel, Claude Simonet, Simone Debout-Devouassoux e Bianca Lamblin ela mesma. Como estes textos, acrescidos de uma carta emocionante de Yvonne a Merleau-Ponty, acabaram não encontrando acolhimento nas Revistas mais próximas, Bianca Lamblin tomou mais tarde a iniciativa de dar outra forma a esses testemunhos, reescrevendo-os em uma unidade.

Segundo Bianca Lamblin, o pai de Yvonne, Charles Picard foi arqueólogo e professor da Sorbonne, motivo que levou a família a se transferir para Atenas. Logo depois do retorno a Paris, em 1936, Yvonne perdeu a sua mãe. Realizou então seus estudos no cours Sévigné, onde se tornou amiga próxima de Collete Duchatel e com esta se relacionou durante 14 anos, até o dia de sua deportação. No último ano, tiveram três professores de filosofia: um encarregado da psicologia, outro de filosofia da ciência e o terceiro, Merleau-Ponty, que tinha como atribuição "metafísica, moral e textos à opção - Epicuro, naquele ano". ${ }^{7}$ Foi este ensinamento que a despertou para a filosofia, especialmente de tradição alemã.

Frequentadora do Café de Flore, Yvonne desenvolveu fervorosamente seus estudos, seguindo assiduamente, juntamente com Claude Simmonet, os cursos de Jean Wahl, que respondia mais do que outros professores ao seu interesse pela fenomenologia. Neste mesmo período, as primeiras obras de Sartre $A$ imaginação, $A$ náusea e $A$ transcendência do ego, segundo o relato de Simonnet, os marcaram

\footnotetext{
${ }^{4}$ Ibidem, p. 03.

${ }^{5}$ LAMBLIN, Bianca. "L’histoire d'Yvonne Picard". Esprit, nº 181, maio de 1992, p. 88-99.

${ }^{6}$ Esta carta encontra-se integralmente publicada no mesmo volume. (PICARD, Yvonne. "Lettre d'Yvonne Picard à Merleau-Ponty - Du dépôt, le 5 août 1942”. Esprit, nº 181, maio de 1992, p. 100-101).

${ }^{7}$ LAMBLIN, Bianca. "L’histoire d’Yvonne Picard”, op. cit., p. 89.
} 
profundamente. ${ }^{8}$ Por outro lado, Yvonne encontrava em Husserl, através de Merleau-Ponty, um pensamento que satisfazia seu ideal de filosofia rigorosa. Apesar da ameaça de Guerra, Yvonne estava decidida a continuar seriamente seus estudos. Durante o inverno de 1938-1939, ela seguiu os últimos cursos de Kojève, cuja originalidade certamente contribuiu para o seu interesse por Hegel. Como nos reporta Lamblin, igualmente contribuiu na sua formação a leitura do livro $A$ infelicidade e a consciência infeliz e a malheureuse de Hegel, de Jean Wahl, sobretudo em um momento em que ela passava a experimentar a solidão radical.

No inverno de 1938-1939, Yvonne Picard e Claude Simmonet conheceram um grupo de estudantes um ano mais novo do que eles. Tratava-se de Raoul Lévy, Jean Kanapa, Bernard Lamblin e Bianca Lamblin. Bianca foi aluna de Simone de Beauvoir e todos os demais foram alunos de Sartre no lycée Pasteur de Neuilly. Nesse grupo de interessados em fenomenologia, rapidamente Bianca Lamblin e Yvonne Picard se tornaram amigas. "Yvonne era beneficiada de uma lisonjeira reputação de profundidade filosófica; nós sabíamos que essa bela jovem cujo olhar iluminava o rosto, prepara um diploma importante: 'Le temps chez Hegel, Husserl e Heidegger". ${ }^{9}$

No outono de 1941, Yvonne obteve uma delegação reitoral no lycée de Sèvres e se mudou para um pequeno hotel, contente por não depender mais do pai, com quem ela vinha se desentendendo profundamente por razões políticas. Em seguida, ela fez o seu estágio de agrégation com Simone de Beauvoir no lycée Camille-Sée. Com o diploma terminado, ela preparava um certificado em antropologia, em 1942, quando o terrível episódio da detenção colocou fim ao seu projeto.

Yvonne Picard havia tomado a decisão de se desligar do Partido Comunista, quando lhe pediram para realizar uma última distribuição de panfletos, os mesmos que a polícia encontrou no canto da porta. Segundo a narrativa de Charlotte Delbo, baseada nas conversas que ela teve com Yvonne Picard no próprio campo de Birkenau, tudo indica que Yvonne conhecia as condições em que foi detida. Ao que tudo indica, a polícia foi inicialmente até a casa de Charles Picard, seu pai, o qual teria fornecido, com uma inconsciência espantosa, o endereço do hotel onde ela morava.

\footnotetext{
${ }^{8}$ Ibidem.

${ }^{9}$ Ibidem, p. 91.
} 
Em seguida, logo ao saber do que realmente se tratava, ele se dirige ao chefe de polícia para tentar liberá-la, sem sucesso. ${ }^{10}$

Conduzida ao Dépôt, chefatura de polícia de Paris, entre 21 e 22 de junho de 1942, Yvonne lá permaneceu até o dia 10 de agosto de 1942, quando foi entregue às autoridades alemãs. Foi em seguida conduzida ao forte Roumainville para, em 24 de janeiro de 1943, ser levada a Birkenau.

Transcrevemos em forma de homenagem esta passagem escrita por Levinas no volume Visages de la Résistance, da Revista Liberté d'Esprit:

Yvonne Picard foi morta em deportação por ter participado da Resistência sem que sua origem tenha sido a causa de seu martírio. Nós temos a lhe render aqui uma devota homenagem - imprescritível - evocando seu pensamento e fazendo assim agitar seus lábios de morte. ${ }^{11}$

\section{O ponto de partida da confrontação entre Husserl e Heidegger}

O único escrito filosófico de Yvonne Picard que restou é o seu trabalho sobre o tempo em Husserl e Heidegger, mencionado acima. Nossa proposta consiste, doravante, em analisá-lo e estabelecer sobre ele uma reflexão crítica no campo da filosofia fenomenológica.

No período após a Guerra, a publicação do trabalho de Yvonne produziu efeitos no campo fenomenológico francês. Giovannangeli lembra-nos que Derrida, em seu mémoire de fin d'études (1953-1954), O problema da gênese na filosofia de Husserl, reporta-se de forma elogiosa à Yvonne Picard, quanto ao fato de ela ter sublinhado o caráter dialético da temporalidade em Husserl. Guarda, porém, a reserva de que a dialética em Husserl seria exclusivamente fenomenológica e de que o idealismo transcendental o teria impedido de fundá-la em uma ontologia da temporalidade do ser. ${ }^{12}$ Embora o texto de Yvonne mereça algumas ressalvas de quem o lê muitas décadas depois da recepção da fenomenologia na França, é preciso considerar que a jovem filósofa estava

\footnotetext{
${ }^{10}$ Ibidem, p. 95. (Cf. DELBO, Charlotte. Le Convoi du 24 janvier. Paris : Minuit, 1978, p. 9-12).

${ }^{11}$ LEVINAS, Emmanuel, "Yvonne Picard". La liberté de l'esprit (Visages de la Résistance), 1987, vol. 17, p. 227-228, apud GIOVANNANGELI, Daniel. "Présentiation”, op. cit., tradução livre, p. 04.

${ }^{12}$ DERRIDA, Jacques. Le problème de la gênese dans la philosophie de Husserl. Paris: PUF, 1990, p. 123, apud GIOVANNANGELI, Daniel. "Présentiation", op. cit., p. o4.
} 
dando os seus primeiros passos e que provavelmente levaria adiante muitas questões ali apresentadas.

O objetivo central de Yvonne Picard é mostrar que a concepção de tempo em Husserl resiste às críticas de Heidegger ao tempo vulgar e apresenta uma vantagem em relação à concepção heideggeriana, pelo seu caráter dialético. Os textos filosóficos utilizados por Yvonne em sua análise são, essencialmente, Ser e Tempo de Heidegger e Lições para uma fenomenologia da consciência íntima do tempo de Husserl. A fenomenologia da existência em Heidegger e a fenomenologia da reflexão em Husserl - embora procurem o existente tal como ele se mostra, ou a experiência que dá sentido a todas as outras - não compreendem da mesma forma "a relação do originário à origem, do autêntico ao inautêntico". ${ }^{13}$ Com o propósito de demonstrar as suas diferenças, a filósofa estabelece como fio condutor da distinção proposta o tema da temporalidade.

Como ponto de partida, Yvonne problematiza a fenomenologia hermenêutica heideggeriana. Segundo a sua leitura, a abordagem filosófica de Heidegger é fundamentalmente analítica. Neste aspecto, ela compara a posição de Heidegger à de Kant. "A pesquisa conduz do empírico ao transcendental, do ôntico ao ontológico. Parece-nos que tal método (não diferindo sensivelmente daquele de Kant) é animado por um tipo de confiança na salvação filosófica”. ${ }^{14}$ Com efeito, este alinhamento com a filosofia transcendental parece bastante acertado, pois Heidegger ele mesmo opunha, no campo transcendental, a sua ontologia à filosofia kantiana. ${ }^{15}$

A partir da analítica existencial, Heidegger coloca em questão o "ser circular do Dasein", ou seja, que a consciência não pode ser sem antes

\footnotetext{
${ }^{13}$ PICARD, Yvonne. "Le temps chez Husserl et chez Heidegger”, op. cit., p. o7. Doravante, todas as citações diretas do texto de Picard constituem traduções livres do texto francês.

${ }^{14}$ Ibidem.

${ }^{15}$ HEIDEGGER, Martin. Ser e Tempo. Edição bilíngue. Tradução de Fausto Castilho. Petrópolis : Vozes e Unicamp, 2012, § 43, p. 558-589. Em Sobre a Verdade, especialmente na Lição 2 - "O esquematismo como elemento determinante da transcendentalidade do Dasein”, Ernildo Stein tece um comentário sobre a relação entre Kant e Heidegger, bem como sobre o que impede este último de recair no psicologismo ou no transcendentalismo. "Então, a crítica que Heidegger fará será também a essas duas soluções, não uma epistemologia, como alternativa a Kant, nem uma antropologia, como Cassirer propõe, mas novamente retornando dos neokantianos a Kant mesmo. Esse retorno a Kant é possível na medida em que Heidegger faz uma reinterpretação de Kant, desde a questão do sentido do ser, isto é, desde, de certo modo, uma leitura de Kant como se os limites, que Kant quer para a metafísica, fossem uma tentativa de ontologia fundamental, de uma 'analítica existencial', entre aspas mesmo". (STEIN, Ernildo. Sobre a Verdade - Lições preliminares ao parágrafo 44 de Ser e Tempo. Ijuí: editora Unijuí, 2006, p. 33).
} 
já compreender. Yvonne não hesita em utilizar o termo "consciência" em Heidegger, como bem acentua Giovannangeli. ${ }^{16}$ A dificuldade formal desta circularidade se dissolve e se compensa no modo como a verdade é garantida de uma vez por todas: o Dasein é por tudo e sempre "na verdade".

No entanto, aquilo que para a autora permanece sem resposta em Heidegger, na via que leva à autenticidade é de onde vem a queda do Dasein enquanto tal. Não lhe quer parecer que para Heidegger a banalidade quotidiana deva retomar os seus direitos mesmo depois do acesso à "verdadeira via". O caráter não empírico da decisão resoluta (Entschlossenheit) faz com que a existência autêntica, uma vez aberto o seu porvir, consista em sempre ter a si o tempo, de jamais perdê-lo. Não haveria dificuldade para o Dasein manter a sua fidelidade a si. Em outros termos, não se colocam mais questões, "a consciência está ao abrigo da dispersão, do esquecimento, da fragmentação e como da falsificação de sua existência em uma série de 'agora' descontínuos". ${ }^{17}$ Por isso, deixa-se de ver por que a decadência é ainda possível, o que se traduz em uma ambiguidade no pensamento de Heidegger.

A partir desta ambiguidade, Yvonne Picard formula algumas interrogações. É uma questão importante saber se haveria um mundo e um ser nesse mundo se o Dasein conseguisse verdadeiramente se manter na existência autêntica. Ademais, ela se interroga se o tempo descrito por Heidegger como autêntico "não se encontra esvaziado de todos os conteúdos (o mundo, as coisas no mundo, os outros Dasein)?"18 E, em seguida, mais radicalmente:

A situação presente que ele revela constitui um presente real, quer dizer, uma presença viva do eu (moi) ao outro que eu-mesmo, - ou bem a solidão que reclama o ser-para-morte é ela tão radical que ela expulsa para trás dela toda compreensão do alter ego ${ }^{19}$

Especialmente esta insatisfação faz reverberar um questionamento que se encontra, de modo similar, embora com

\footnotetext{
${ }^{16}$ GIOVANNANGELI, Daniel. "Présentiation", op. cit., p. 05.

${ }^{17}$ PICARD, Yvonne. "Le temps chez Husserl et chez Heidegger", op. cit., p. o8.

${ }^{18}$ Ibidem, p. o9.

${ }^{19}$ Ibidem.
} 
perspectivas diferentes, em pelo menos duas leituras de Heidegger: tanto a de Ricœur quanto a de Levinas. Ricœur constrói a sua concepção hermenêutica não necessariamente contra Heidegger, mas a partir de sua crítica à "via curta" da ontologia heideggeriana, à qual ele opõe a "via longa”, tendo como aspiração a ontologia da compreensão, passando necessariamente pelas hermenêuticas particulares, recobrindo progressivamente o plano semântico, reflexivo e existencial. ${ }^{20}$

Levinas, por seu turno, de modo mais radical, contrapõe o seu pensamento a Heidegger porque percebe na analítica do Dasein um fechamento do eu ao Outro, ponto nodal de sua crítica à ontologia heideggeriana. O primado da ontologia em Heidegger afirmaria a prioridade do ser em relação ao ente, fazendo subordinar a relação com alguém, que é um ente, ao ser do ente, ou seja, subordinando a ética à ontologia. ${ }^{21}$

Yvonne Picard, por um gesto singular, apresenta uma leitura que se pode chamar de dialética, explicitando que o problema na ontologia de Heidegger estaria na impossibilidade de encontrar uma síntese, uma conciliação, entre os dois extremos da autenticidade e da inautenticidade. Esta síntese somente poderia ser operada como superação do conflito ôntico-ontológico, mas ela seria impossível de se fazer de modo puramente analítico. ${ }^{22}$ Daí a sua suspeita sobre a famosa definição de Heidegger segundo a qual "a essência do Dasein reside em sua existência". ${ }^{23}$ Há um risco, por conta desta definição, de que a essência seja tomada "como já aí na existência, perfilada, projetada", sem que um progresso verdadeiro seja realizado. Uma posição que também nos faz lembrar a tese adotada por Sartre mais tarde. ${ }^{24}$

Essa mesma ambiguidade é colocada sob o plano da temporalidade. Somente há um modo, numa única direção - o porvir -, de o Dasein existir, o mundo se mundanizar e o tempo se temporalizar. As estruturas originais do Dasein e os modos temporais inautênticos, no

\footnotetext{
${ }^{20}$ RICEUR, Paul. "Existence et herméneutique”. Le conflit des interprétations - essais d’herméneutique. Paris : Seuil, p. $07-28$.

${ }^{21}$ LEVINAS, Emmanuel. Totalité et infini - Essai sur l'extériorité. Paris : Kluwer, 1986 (1971), p. 36.

${ }^{22}$ PICARD, Yvonne. "Le temps chez Husserl et chez Heidegger”, op. cit., tradução livre, p. 10.

${ }^{23}$ HEIDEGGER, Martin. Ser e Tempo, op. cit., p. 139.

${ }^{24}$ SARTRE, Jean-Paul. L'existentialisme est un humanisme. Paris: Gallimard, 1996 (1946), p. 26.
} 
entanto, seriam "consequências rigorosas da temporalização a partir da temporalidade originária”. ${ }^{25}$

Para uma solução a essa crítica, Yvonne entende necessário, apesar de todos os artifícios da consciência para se ocultar a si-mesma, uma forma única de temporalidade, como operação constituinte e fonte de todas as determinações. É na concepção de tempo husserliana que Yvonne antevê uma solução, uma vez que o tempo, não teria para Husserl a uniformidade de sentido apresentada pelo tempo heideggeriano.

O tema do tempo se revela, portanto, muito mais do que um entre outros temas do confronto entre Husserl e Heidegger. Ele se caracteriza como o ponto de inflexão na fenomenologia para uma releitura de Heidegger a partir de Husserl. Em outros termos, a partir da questão da temporalidade, Yvonne Picard empreende um retorno à fenomenologia reflexiva.

\section{O tempo na fenomenologia de Husserl}

O movimento de retorno à temporalidade em Husserl realizado por Yvonne Picard tem por principal objetivo demonstrar que a teoria husserliana não desmorona sob as críticas de Heidegger. As precauções tomadas por Husserl seriam semelhantes às exigências heideggerianas.

O exercício aqui proposto será o de acompanhar o raciocínio da filósofa, retomando o princípio de que o tempo em Husserl não é o tempo psicológico, mas o tempo depois da redução transcendental, ou seja, depois da suspensão de juízo sobre o mundo natural e suas evidências ingênuas. Não se trata de um tempo da natureza e tampouco uma recepção de conteúdos que se sucederiam por uma espécie de fatalidade inexplicável e externa à consciência. "Não se trata de um devir, trata-se da consciência de um devir, uma consciência do tempo." 26 Tanto como em Heidegger, para Husserl o tempo não seria uma corrente de consciência ou escoamento, pois estas metáforas somente seriam aplicáveis ao objetivável, mas jamais ao tempo em sua fonte.

\footnotetext{
${ }^{25}$ PICARD, Yvonne. "Le temps chez Husserl et chez Heidegger”, op. cit., tradução livre, p. 11.

${ }^{26}$ Ibidem, p. 12.
} 
Quando Husserl emprega o termo fluxo (Zeitfluss), ele designa com isso o fenômeno original da temporalidade, a partir de uma reorganização contínua da consciência, sentido de sua espontaneidade e não-inércia. Este termo não deve causar confusão: não se trata meramente de uma sucessão de "agora(s)" (Jetztfolge), como uma espécie de sequência externa e incompreensível, tampouco um modo de expressar que estamos no tempo.

Yvonne Picard recorre ao Suplemento VI das Lições para uma fenomenologia da consciência íntima do tempo para mostrar em que sentido deve ser compreendida a noção de "fluxo". O fluxo absoluto é préempírico, como consciência transcendental. Porém, diferentemente da consciência transcendental de Kant, cujo "eu penso" é criticado por Heidegger, Husserl considera que o "eu" é apenas uma contrapartida da dispersão ôntica, sendo ele mesmo uma unidade ôntico-fática. A consciência do tempo "é síntese do um e do múltiplo, nem unidade por ela mesma fora da multiplicidade, nem multiplicidade privada de unidade”. ${ }^{27}$

O que significa, portanto, que o fluxo absoluto é atemporal (zeitlos)? Antes de tudo, é preciso considerar que o ser concreto, apenas pensável como duradouro, em continuidade, é um processo que pode ser de mudança ou de repouso. No entanto, como afirma Husserl, o fluxo absoluto é uma mudança que não comporta a alternativa da não-mudança, tal como no processo de ordem empírica. Trata-se do problema da unidade da consciência que, em Husserl, não é dada pelo vivido, mas que este supõe. No fluxo absoluto, não há nenhum pedaço que possa se transformar em não-fluxo. ${ }^{28}$

Husserl finalmente não se satisfaz com a palavra "fluxo" aplicada à temporalidade originária enquanto subjetividade absoluta, mas qualquer forma de nominação levaria ao risco de tomar emprestado um tipo de objetividade. Sendo o fluxo a forma da temporalidade, não se trata este fluxo de uma forma vazia, mas de uma estrutura, de um esquema no qual a consciência é afetada a cada instante de uma "impressão emanante" (impression jaillissante). ${ }^{29} \mathrm{~A}$ novidade não brota da forma ela mesma, do modo como a consciência é afetada pelas sucessivas impressões. Essa

\footnotetext{
${ }^{27}$ Ibidem, p. 13.

${ }^{28}$ Ibidem. (Cf. HUSSERL, Edmund. Vorlesungeng zur Phänomenologie des inneren ZeitbewuBtseins. Tübingen: Max Niemeyer, 1980 (1928), p. 433).

${ }^{29}$ PICARD, Yvonne. "Le temps chez Husserl et chez Heidegger", op. cit., p. 14.
} 
F. C. L. de Castro - Yvonne Picard e a fenomenologia entre Husserl e Heidegger | 789

novidade não interessa tanto por sua alteração qualitativa que ela submete a um conteúdo, mas por ser uma novidade insubstituível e recomeçada sem cessar. É esse aspecto que liga a impressão à forma da temporalidade que interessa à Yvonne Picard.

\section{A dialética do tempo na fenomenologia}

O passo seguinte consiste em avaliar, a partir da fenomenologia, a dimensão de acessibilidade ao porvir. Afirmar que a consciência toma forma, toma tempo, é o mesmo que dizer que ela se temporaliza. Ao se temporalizar, ela transforma o "agora" precedente em "agora" retido, implicado a cada vez pelo novo "agora". Por outro lado, ele desenvolve um horizonte de protensão, dirigido ao futuro, ou seja, como anunciador de um porvir que novamente lhe fará recair no passado. Esta espécie de cauda da retenção pode ser mais ou menos longa, a depender do modo como a consciência vivência a série de aparições. Há, no entanto, uma limitação. Uma parte deste passado, não imediato, ou seja, mais distante, somente seria acessível de modo indireto, necessitando de um ato específico da consciência, a representação descontínua que é a rememoração. Essa descontinuidade também poderia ser pensada na direção oposta, o porvir, não mais como protensão em continuidade, mas no sentido da representação projetiva.

A mesma estrutura pode ser encontrada em Heidegger, considerando-se que o Dasein porta junto consigo e não pode jamais fazer desaparecer suas fronteiras, os horizontes fechados a partir dos quais todo conhecimento se funda. ${ }^{30}$ Para Heidegger, a estrutura apriorística do tempo é a de ser em três termos, três ek-stases, comportando-os em cada instante como unidade temporal extática. Nesse campo de presença no qual a consciência se absorve totalmente nela mesma, há uma cooriginaridade, uma contemporaneidade do futuro, do passado e do presente. A temporalização não se faz pedaço a pedaço, primeiro uma parte e depois outra, mas de modo totalmente integrado.

Essas fórmulas heideggerianas são apenas a transposição da ideia husserliana de um presente total onde é impossível determinar uma parte fixa a qualquer uma das dimensões do tempo - cada fase deste tipo

${ }^{30}$ Ibidem, p. 16. 
formando um "bloco" (Zeitbewusstsein, §38), uma coexistência absoluta, como uma camada (Schicht) ou ainda uma onda que escoa e se desintegra de um só golpe. ${ }^{31}$

Retornando a Husserl, o agora (no sentido estreito do instante) seria o núcleo do campo de presença (o presente em sentido mais largo), embora o instante por si mesmo seja intangível ou evasivo. O instante é um infinitesimal, limite ideal das duas intencionalidades (protensional e retencional) que se orientam na sua direção, de maneira que o presente, no sentido largo encerra esses limites ainda que não possa fixá-los. O que Yvonne Picard chama de caráter dialético do tempo é o fato de que a impressão original e a retensão somente possuem sentido concreto uma em relação à outra. Há uma relação dialética entre a forma do tempo e a materialidade da impressão, no sentido de que o tempo é indivisivelmente acontecimento, enquanto impressão, e estrutura de retenção unificando o tempo inteiro.

Síntese criadora, sempre recomeçada, de atividade e passividade, de permanência e de sucessão, de necessidade e de contingência, de liberdade e de compromisso, tal é o tempo husserliano. ${ }^{32}$

Nessa forma de considerar a autoconstituição do tempo, Husserl não daria nenhum tipo de primazia ao presente no sentido da crítica heideggeriana, de uma equivalência entre um presente e outro, na série monótona de uma linha reta, pela qual se vive a banalidade quotidiana. Ao contrário, o tempo de Husserl seria o da continuidade absoluta, em que o novo agora não apaga o anterior, pois este é guardado intencionalmente pela retenção. Mesmo que por reiteração os mais antigos presentes desapareçam do campo da intencionalidade atual, nada impede que sejam recuperados pela rememoração, não sendo esta uma dispersão, mas o modo de ser da própria reflexão. ${ }^{33}$ Além disso, Husserl admite, tanto como Heidegger, que o porvir tem um primado na constituição do tempo.

\footnotetext{
${ }^{31}$ Ibidem, p. 17.

${ }^{32}$ Ibidem, p. 18.

${ }^{33}$ Ibidem, p. 19.
} 
Há três aspectos em que Husserl e Heidegger convergem em suas descrições, quanto às consequências negativas do primado do porvir. ${ }^{34} \mathrm{~A}$ primeira dessas consequências é que o porvir não é dado à consciência ao modo de uma coisa. Se o futuro é indeterminável, é porque justamente não se trata de um objeto. O porvir não se equipara a um defeito de conhecimento que podemos ter diante de uma coisa, mas de um defeito por princípio do saber. Por isso Husserl se refere ao futuro como a consciência aberta como diante do abismo e Heidegger, por sua vez, afirma que o Dasein é o ponto de apoio do nada.

A segunda consequência é que a consciência que tem um porvir não é tampouco uma coisa. Nem a prisioneira dos acontecimentos passados, nem a mera soma dos acontecimentos que ela suportou, a consciência tem a tendência imanente de se ultrapassar. Por essa razão, Heidegger afirma que o Dasein é sempre mais do que de fato ele é. Tal qualidade pode ser aproximada da concepção husserliana sobre a protensão, que é como uma "avidez" de toda consciência atual, unificada em direção ao porvir, a uma promessa de preenchimento intencional. ${ }^{35}$

A terceira e última consequência do primado do porvir é que a consciência que tem um porvir não tem ideias que possam ser equiparáveis a coisas fechadas. Tanto para Husserl (a intencionalidade mais profunda da consciência) como para Heidegger (o seu poder-ser mais próprio do Dasein), o porvir é o que permite o acesso às coisas e ao seu ser mais verdadeiro. ${ }^{36}$

O porvir é o que permite enfim ao Dasein "voltar a si mesmo". A decisão antecipadora assegura a "totalização" da existência - ela é a prova de seu poder de formar um todo (Ganzseinkönnen). Essas fórmulas são o equivalente da demonstração husserliana da unificação da consciência pelo porvir. ${ }^{37}$

No entanto, essas equivalências que podemos encontrar entre as concepções de tempo em Husserl e Heidegger dizem respeito às consequências negativas do primado do porvir (o que o porvir não é). $\mathrm{O}$

\footnotetext{
${ }^{34}$ Ibidem, p, 19-26.

${ }^{35}$ Ibidem, p. 20.

${ }^{36}$ Ibidem.

${ }^{37}$ Ibidem, p. 21.
} 
que os diferencia é como cada um concebe o que há de positivo, a natureza desta primazia.

Em Heidegger, o movimento em direção à morte, na autenticidade, se coloca para além de toda queda e libera para sempre o Dasein. Em Husserl, ao contrário, nunca somos em algum momento "mestres do tempo", ${ }^{38}$ pois o porvir é sempre visto do presente e este sempre renasce, de modo que a consciência não é jamais realizada, ou seja, em possessão total da verdade. Isso não significa que Husserl desconheça o problema da morte, pois o tempo não configura para ele uma aparência de eternidade atemporal. Não se trata de abandonar o ponto de vista do presente na constituição do tempo para apenas aceitar o ponto de vista do futuro. $\mathrm{O}$ eventual acento a uma das dimensões do tempo não faz desaparecer a forma original da consciência - retenção, protensão e impressão. "Segundo Husserl, há bem um primado do porvir, mas jamais o ponto de vista do porvir, sempre ponto de vista sobre ele. É impossível renunciar essa condição de ser situado no presente."39

O problema que Yvonne Picard detecta na temporalidade em Heidegger é que o retorno do Dasein sobre si diante da morte exigiria uma concepção dialética do tempo. Como Heidegger não reconheceu essa exigência, depois da decisão resoluta o "tempo está para ele como parado", como se possível fosse um domínio total da existência: nenhum novo porvir pode aparecer depois dele. Ora, a concepção dialética que falta à Heidegger encontra-se em Husserl, cuja consequência é a repetição indefinida do tempo. Daí o problema do tempo autêntico de Heidegger. Se o ser-no-mundo é para Heidegger uma decaída, uma queda, resultante de uma perda do tempo verdadeiro, correlativamente, não parece que possa haver um mundo após da decisão resoluta frente à descoberta do ser-paramorte.

Sem mundo, sem ainda a presença a outrem, sem história, é por isso que a morte assim compreendida isola radicalmente. Todas as afirmações citadas no início: o Dasein autêntico existe essencialmente como realizando uma co-presença com outros, seu destino está ligado a um

\footnotetext{
${ }^{38}$ Ibidem.

${ }^{39}$ Ibidem, p. 23 (o grifo é nosso).
} 
F. C. L. de Castro - Yvonne Picard e a fenomenologia entre Husserl e Heidegger | 793

destinação [destinée], ele pertence a priori a uma comunidade, a um povo, a uma geração - são assim falaciosas. ${ }^{40}$

Nesse sentido, o tempo que não é intencional ou dialético nos impossibilita de penetrar no mundo único e comum da intersubjetividade, para além do espaço fático da banalidade quotidiana, mas como um verdadeiro espaço no ambiente das coisas.

\section{Sobre o tempo como intencionalidade}

Resta ainda, como última etapa de nossa análise sobre o trabalho de Yvonne Picard, esclarecer por que o tempo dialético e a intencionalidade são a mesma coisa, considerando que "o movimento de temporalização é movimento de objetivação”. ${ }^{41}$ Uma nova questão se apresenta quando se coloca em evidência que o passado pode significar duas coisas, tanto a vivência, a Erlbenis, quanto o objeto transcendente, o objeto percebido. Há sempre duas formas de se lembrar do acontecimento vivido, tanto daquilo que foi o conteúdo, o objeto da vivência, quanto da vivência ela mesma. Picard retoma assim as noções husserlianas de "intencionalidade longitudinal", que assegura a passagem de um campo de presença a outro, e a "intencionalidade transversal", estabelecida em um nível de constituição mais complexo, que assegura a unidade da síntese constitutiva dos objetos transcendentes. Por essa mesma razão, pode-se apreciar a unidade da consciência de duas formas distintas, como "unificação imediata", através da qual se cria uma identidade contínua de quem eu sou (por retenção e protensão), e como "unificação mediata”, que se realiza na rememoração, na lembrança. ${ }^{42}$

O passo dado por Husserl, além de haver reconhecido esses dois tipos de intencionalidades em movimento sob a consciência do tempo, foi mostrar que a sua separação se deve apenas à clareza da explicação, pois essas duas formas de unificação são inseparáveis, como "duas faces de uma só e mesma coisa”. ${ }^{43}$ Segundo Picard, uma dessas formas diz respeito à percepção, ou ao campo de presença, e a outra à rememoração refletida.

\footnotetext{
${ }^{40}$ Ibidem, p. 26.

${ }^{41}$ Ibidem.

${ }^{42}$ Ibidem, p. 28.

${ }^{43}$ Cf. HUSSERL, Vorlesungeng zur Phänomenologie des inneren ZeitbewuBtseins., §39, p. 432.
} 
O recurso à lembrança não é um acaso se quisermos elucidar o que é a intencionalidade.

No campo de presença, a percepção e o percebido são absolutamente simultâneos na consciência impressional, não no sentido de um encontro entre dois termos estranhos, mas como fonte de toda presença e, de forma derivada, de toda ausência de um objeto. É enquanto retrospecção que o objeto como tal ganha corpo, uma vez que ele já estava lá (não como objeto, mas na impressão). "Ao colocá-lo pela primeira vez expressamente, ela [a consciência] lhe confere sua natureza de coisa uma, sua identidade". ${ }^{44} \mathrm{O}$ segredo da intencionalidade, portanto, de que a consciência é consciência de alguma coisa consiste em que a impressão original, passando, e se tornando retenção, não apenas afasta um momento da consciência constituída e outro, mas se trata da própria distinção entre a consciência e aquilo de que ela é consciência. "Ela faz surgir a distinção entre aparição (Erscheinung) e o aparecido (Erscheinendes), que é a distinção mesma do presente e do passado." ${ }^{45}$ Não haveria, portanto, necessidade de uma intervenção especial, como a intervenção divina, para que o objeto seja tematizado, mas apenas a própria temporalização da consciência.

Uma nova questão dificulta ainda um pouco a análise. Ao mesmo tempo em que a retenção da impressão opera, assim como a retenção da retenção etc., fixando uma identidade ao objeto, pode ocorrer (como de fato ocorre com frequência) que o objeto ele mesmo se transforme, seja, por exemplo, uma melodia, seja um pássaro que passa voando. Há, portanto, a duração dos campos perceptivos, campos de presença, e duração, com ou sem modificação da unidade destes fenômenos, e a duração das próprias coisas, no seu tempo, com ou sem modificação. ${ }^{46}$

A partir dessas análises, Picard pretende mostrar que a medida do agora de objetos contemporâneos, sobre o ritmo, a velocidade, a duração ela mesma, é ainda um problema a ser resolvido. A simples convenção sobre aquilo que é presente a todos não poderia constituir uma medida, não atinge a medida comum que deve ser pré-intelectual e presente à consciência vivente de cada um. Heidegger ele mesmo responde a esta questão afirmando que

\footnotetext{
${ }^{44}$ PICARD, Yvonne. "Le temps chez Husserl et chez Heidegger", op. cit., p 29.

${ }^{45}$ Ibidem.

${ }^{46}$ Ibidem, p. 31.
} 
todos dizem "agora" significando coisas diferentes a cada vez, no tempo e no espaço. ${ }^{47}$ No entanto, segundo Picard, Heidegger não explica como chegamos a um acordo, como a publicidade do tempo se estabeleceria na confusão inevitável. A questão é crucial, pois teria Heidegger, com isso, deixado escapar o que precisamente é a contemporaneidade e a relação com o outro.

\begin{abstract}
Essa contradição não é ela a prova de que ele não conseguiu mostrar o que ele esperava, e que, sob pretexto de reencontrar o tempo autêntico na sua pureza, ele deixou escapar a natureza verdadeira, que comporta essencialmente a contemporaneidade? Se ele tivesse visto isso, ele teria podido dar um sentido novo ao ser-no-mundo e à co-presença de outrem, e não rejeitar um e outro na inautenticidade. ${ }^{48}$
\end{abstract}

O retorno a Husserl permitira solver este problema. Há para Husserl um tempo imanente para todos os objetos, que se torna o prelúdio e a condição do tempo objetivo, assim como "o ritmo essencial e fatal da coexistência de todas as consciências”, razão pela qual, o que quer que aconteça ou que alguém faça, "nenhum 'agora' é definitivo: é em suma, o jorro caraterístico do fluxo originário da temporalidade". ${ }^{49} \mathrm{O}$ tempo da imanência e o da transcendência correm em paralelo, um aparece através do outro, sem qualquer subordinação de um a outro, que nos remeteria aos polos do psicologismo e do hilozoísmo.

Como diz Heidegger, o espaço é um presente absolutizado, na medida em que o seu alargamento é uma intrusão, uma usurpação e, finalmente, um erro; enquanto em Husserl este presente tem o direito de se estender, pois ele não faz desaparecer a sucessão. Esta seria a razão pela qual, segundo Picard, Heidegger teria de pagar um preço alto por não ter sobre o tempo uma concepção dialética, cometendo o mesmo erro que ele pretende censurar: "seu presente (aquele do tempo autêntico, porém) se eternizou"..$^{\circ}$

Na resposta de Husserl, o espaço não se deduz do tempo. E ele deixa claro que no campo de presença originário, onde a consciência é o que ela percebe, a simultaneidade supõe já a sucessão, o imediato supõe a mediação. A desintegração possível entre a sucessão enquanto tempo puro e o espaço da

\footnotetext{
${ }^{47}$ HEIDEGGER, Martin. Ser e Tempo, op. cit., §79, p. 1098-1111.

$4^{8}$ PICARD, Yvonne. "Le temps chez Husserl et chez Heidegger", op. cit., p. 33.

${ }^{49}$ Ibidem.

${ }^{50}$ Ibidem, p. 36 .
} 
memória e da interiorização reencontra-se em um nível de integração mais elevada, sob a forma de uma simultaneidade de um novo espaço-tempo, o da contemporaneidade.

\section{Considerações finais}

As suspeitas levantadas por Yvonne Picard sobre o tratamento adequado ao ser-no-mundo e à relação com o outro na ontologia de Heidegger, a partir das consequências da distinção entre inautenticidade e autenticidade, coloca-a no centro de um espinhoso debate em fenomenologia.

A elucidação do confronto entre Heidegger e Husserl e o acolhimento de fenomenologia da consciência do tempo, mesmo após Ser e Tempo de Heidegger, é bastante instrutivo sobre o contexto de leitura e de recepção da fenomenologia na França no final dos anos 1930 e início dos anos 1940. Logo em seguida foram publicados importantes livros como O Ser e o Nada de Sartre (1943) e Fenomenologia da Percepção de Merleau-Ponty (1945), entre outros, onde se teve igualmente de se questionar sobre a recepção do pensamento de Husserl e Heidegger. Permaneceria vivo o projeto de uma fenomenologia reflexiva, ou restaria algo dela mesmo após Heidegger?

O presente artigo não teve como propósito responder definitivamente essa questão, senão mostrar em que sentido, para Yvonne Picard, em seu emblemático texto O tempo em Husserl e Heidegger, seria necessário apresentar uma espécie de correção a Heidegger através da descrição da consciência do tempo em Husserl. Espera-se que o nome e o belo trabalho filosófico de Yvonne Picard fiquem registrados em nossa memória.

\section{Referências bibliográficas}

DELBO, Charlotte. Le Convoi du 24 janvier. Paris : Minuit, 1978.

DERRIDA, Jacques. Le problème de la gênese dans la philosophie de Husserl. Paris: PUF, 1990.

GIOVANNANGELI, Daniel. "Présentiation". Philosophie, nº 100, 2008, éditions Minuit, p. o3-06.

HEIDEGGER, Martin. Ser e Tempo. Edição bilíngue. Tradução de Fausto Castilho. Petrópolis : Vozes e Unicamp, 2012. 
F. C. L. de Castro - Yvonne Picard e a fenomenologia entre Husserl e Heidegger | 797

HUSSERL, Edmund. Vorlesungeng zur Phänomenologie des inneren ZeitbewuBtseins. Tübingen: Max Niemeyer, 1980 (1928).

LAMBLIN, Bianca. "L’histoire d'Yvonne Picard”. Esprit, nº 181, maio de 1992, p. 88-99.

LEVINAS, Emmanuel, "Yvonne Picard". La liberté de l'esprit (Visages de la Résistance), 1987, vol. 17, p. 227-228,

. Totalité et infini - Essai sur l'extériorité. Paris : Kluwer, 1986 (1971).

PICARD, Yvonne. "Le temps chez Husserl et chez Heidegger". Philosophie, nº 100, 2008, éditions Minuit, p. 07-37.

. “Lettre d’Yvonne Picard à Merleau-Ponty - Du dépôt, le 5 août 1942”. Esprit, nº 181, maio de 1992, p. 100-101.

RICEUR, Paul. "Existence et herméneutique". Le conflit des interprétations - essais d'herméneutique. Paris : Seuil, p. 07-28.

SARTRE, Jean-Paul. L'existentialisme est un humanisme. Paris: Gallimard, 1996 (1946).

STEIN, Ernildo. Sobre a Verdade - Lições preliminares ao parágrafo 44 de Ser e Tempo. Ijuí: editora Unijuí, 2006.

\section{Endereço postal:}

Programa de Pós-graduação em Filosofia da PUCRS

Av. da Ipiranga, 6681, prédio 5 - Porto Alegre, RS, Brasil

Data de recebimento: 07-09-2017

Data de aceite: 04-12-2017 